\title{
Behavior and Substance Addictions: Is the World Ready for a New Category in the DSM-V?
}

To the Editor:

January 12, 2007

We read with interest the letter to the editor by Block ${ }^{1}$ that identifies some interesting points of discussion in the context of the article by Aboujaoude and colleagues. ${ }^{2}$ Block describes the distinction between various terms such as "problematic Internet use," "compulsive computer use" and "computer addiction" rather meticulously and, to conclude, uses the phrase "potential disorder."' Our objection is to the use of the phrase "potential disorder."

There has been much discussion about the addition of a new diagnostic category in the forthcoming Diagnostic and Statistical Manual of Mental Disorders, Fifth Edition for behaviors that are considered to be at the interface of obsessive-compulsive disorder, on the one hand, and substance addiction, on the other. In fact, the November 2006, CNS Spectrums Editor's Letter is dedicated to characterizing the neurobiological correlates and similarities in terms of fronto-striatal circuit impairments. ${ }^{3}$

Having received our medical education and some clinical experience in India, we would like to point out that all these proposed categories (Internet addiction, compulsive buying, etc.) have a socioeconomic aspect to them that is getting somewhat lost in the rut of finding neurobiological underpinnings for all psychiatric disorders. If these were to become diagnostic categories what would be their equivalents in the countries of Asia and Africa where thousands die of poverty and hunger everyday? Most of the reported studies are from the United States. Should there not be some international studies across various socioeconomic-cultural backgrounds before new diagnostic categories are created in the $D S M-V$ ? It becomes all the more important, since the $D S M$ is a diagnostic system that is followed rather universally across the globe along with International Classification of Diseases. This is not to undermine the need for clinical attention for these problematic behaviors, but just to highlight that if they were to figure in DSM-V it may be a good idea to identify these as problem behaviors identified predominantly in the US population, somewhat similar to the section on culture bound syndromes.

In our opinion, for a behavior to be considered a disorder it should have universal features across different ethnic, socioeconomic-cultural backgrounds so that clinicians can communicate across the globe without much confusion. In this day of evidence-based medicine, this would only be possible if there would be large-scale international epidemiological studies to support these as diagnostic categories.

Sincerely,

Amitabh Parashar, MD

Anjali Varma, MD

\section{REFERENCES}

1. Block J. Prevalence underestimated in problematic internet use study. CNS Spectr. 2007:12:14-15.

2. Aboujaoude E, Koran LM, Gamel N, Large MD, Serpe RT. Potential markers for problematic internet use: a telephone survey of 2,513 adults. CNS Spectr. 2006:11:750-755

3. Hollander E. Behavior and substance addictions: a new proposed DSM-V category characterized by impulsive choice, reward sensitivity and fronto-striatal circuit impairment. CNS Spectr. 2006;11:814.

Dr. Parashar is a third-year internal medicine resident and Dr. Varma is a third-year psychiatry resident both at the University of Virginia Roanoke Salem Program in Roanoke.

Disclosure: Drs. Parashar and Varma do not have an affiliation with or financial interest in any organization that might pose a conflict of interest. 
THE AUTHOR RESPONDS

To the Editor:

January 16, 2007

Parashar and Varma suggest that compulsive or pathologic computer use is primarily seen and studied in relatively wealthy countries, like the United States. Therefore, they consider it a culturally and economically bound syndrome that should be sidelined or omitted from the Diagnostic and Statistical Manual of Mental Disorders, Fifth Edition. Unfortunately, pathologic computer use is not specific to North America or Europe; it is a worldwide syndrome that fits somewhere along the spectrum between addiction and compulsion.

Pathologic computer use is a diverse set of activities, ranging from repetitive and time consuming viewing of online pornography to compulsively self-destructive E-mailing and instant messaging. Perhaps, though, the greatest area of concern is around addictive-like computer game play.

World of Warcraft, the most popular Internetbased game today is a massively multiplayer role-playing game (MMORPG). As of 2007, over 8 million people worldwide subscribe and pay monthly dues to play. ${ }^{1}$ According to the company that owns it, over 3.5 million of the players are in China; 1.5 million more than play it in North America. ${ }^{1}$ In October 2004, 15 million people played MMORPGs in Asia. At that same time, it was estimated there were only $\sim 2$ million users in the US. ${ }^{2}$ Thus, computer game play is a significant issue in Asia. Indeed, due the amount of time spent playing such games and concern over the consequences, ${ }^{3,4}$ the Chinese, Thai, and Vietnamese governments have placed restrictions on how long their citizens can use such games in one sitting.

With regards to research, I am in agreement that there needs to be more. However, the research that has been published is decidedly international and consistent in its findings. To name but a few, researchers in Pakistan, Holland, Sweden, Taiwan, South Korea, China, and England have all published on the phenomenon, using their own patient populations. In South Korea alone, according to Business Week, ${ }^{5}$ there are over 40 treatment centers for pathologic computer use; I know of only three in the US.

We need to do better.
Parashar and Varma are correct in that there are cultural factors that influence whether the pathologic computer use expresses itself. Obviously, one would need access to a computer before they could compulsively use it. But, there are other considerations. For example, one reason pathologic computer use has received so much attention in Asia is the popularity of inexpensive Internet cafes there. When several healthy young men started dying in front of computers after sitting and playing games for $\geq 16$ hours, it got the public's attention. In one case report, ${ }^{6}$ the postmortem pathology on a 24year-old male found a pulmonary embolus-an "eThrombosis," as the pathologist described it. In the US and Europe, such events also occur.? However, unlike in Asia, computer use is predominantly within one's own home; the deep vein thrombosis or game-induced seizure ${ }^{8}$ might occur with few or no witnesses and others may fail to notice the role of pathologic computer use as a contributing factor.

There are numerous other cultural differences around computer use. A disturbing example comes out of South Korea. There, many young computer users informally compete to have the best adorned online images-images known as "avatars" that often appear next to the messages that the children post to the Web. Users are given the basic avatar free but companies then sell, for real money, virtual apparel that can be used to embellish the image. Thus, one might be able to buy their avatar a cigar or a hat for a few dollars. In a peer-reviewed report, ${ }^{9}$ researchers briefly describe an 11-year-old girl who spent $\$ 1,450$ on such items. After being confronted, she committed suicide. In addition, the authors noted several other young girls who would get older men to buy their avatar items, in exchange for online sex chat or "cyber prostitution." ${ }^{9}$ While such issues certainly occur in the US, they take on a different form; avatars do not carry the same cultural significance here.

Parashar and Varma also raise a complex question regarding the linkage of the DSM-V and the International Classification of Diseases. There are others who are much more qualified than I to address this issue. I am uncertain whether "pathologic computer use" ought to be coded directly into the DSM-V. Rather, I simply want that the syndrome be recognized in some methodical fashion so that we begin to work out functional treatments. 
Fundamentally, I believe the compulsive computer use, in all its forms, has a common root: the computer-based activity is pleasurable as it relieves anxiety, reduces aggressive impulses, and is a sexual outlet.

When it stops functioning in that manner, the anxiety, aggression, and sexual impulses reemerge or the individual tries to defend against them by redoubling their efforts and increasing their computer time. If the pattern repeats, eventually the computer use becomes the primary problem.

In my practice, I identify pathologic computer use using the mnemonic: SIGNS. Note that the symptoms are independent of the specific way the computer is being compulsively used.

- Sleep-pattern disturbance (delay of onset)

- Irritability before and after computer use

- Guilt and attempts to hide/purge computer use

- Nightmares and dreams about computer use

- Social avoidance

Finally, in intervening, caution is warranted. Because the computer is being used to ward away toxic emotions and conflicts, simply removing or restricting its use often triggers despair or rage. Without adequate supports in place, suicide or homicide may result. ${ }^{10, n}$

Sincerely, Jerald J. Block, MD

\section{REFERENCES}

1. World Of Warcraft Surpasses 8 Million Subscribers Worldwide. Available at: http:/// whw blizzard.com/press/070111 shtml. Accessed Jantary 16,2007.

2. NCsoft Corp. NCsoft's Investor Relations Report. Seoul. South Korea: NCsoft Corp.; October, 2004.

3. Chinese gamer sentenced to life. BBC News Web site. Avallable at: http:/news.bbe co. uk/2/hi/technology/4072704.stm. Accessed January 16, 2007

4. S Korean dies after games session. BBC News Wob site. Available at: htto://news. bbc.co.uk/1/hi/technology/4137782.stm. Accessed January 16, 2007

5. Online gaming: Korea's gotta have it. BusinessWeek Online Web site. Available at: http://wwwbusinessweek.com/magazine/content/06_37/64000070.htm. Accesed January 16,2007

6. Lee $\mathrm{H}$. A new case of fatal pumonary thromboembolism associated with prolonged sitting at computer in Korea. Yonsei Med J. 2004:45:349-351.

7. Computer game teenager gets DVT. BBC News Web site. Available at: http://news boc.co.uk/2/hi/health/3441237.stm, Accessed January 16, 2007

8. Chuang YC. Massively multiplayer online role-playing game-induced seizures: a neglected health problem in intemet addiction. Cyberpsychol Behav. 2006;9:45 -456.

9. Lee 0 , Shin M. Addictive consumption of avatars in cyberspace. Cyberpsychol Behav. 2004:7:417-420.

10. Block WJ. Pathological computar game use. Psychiatric Times. 2007;24:49,51

11. Allison SE, Wahlde L., Shockley T, Gabbard GO. The development of the self in the era po the internet and role-palying fantasy games. Am J Psychiatry. 2006;163:381-385.

Dr. Block is a practicing psychiatrist in private practice in Portiand, Oregon, and he is affiliated with Oregon Health and Science University in Portland. He is also the co-founder of SMARTguard Software.

Dr. Block does not have an affiliation with or financial interest in any organization that might pose a conflict of interest.

Please send letters to the editor to: CNS Spectrums, c/o Eric Hollander, MD, 333 Hudson St., 7th Floor, New York, NY 10013; E-mail: vi@mblcommunications.com.

\title{
Now Available Online at www.cnsspectrums.com CME-ACCREDITED SUPPLEMENT CME]
} An expert review of clinical challenges in psychiatry and neurology

\section{Recent Advances in the Treatment and Management of Excessive Daytime Sleepiness}

\author{
by Jed Black, MD, Stephen P. Duntley, MD, \\ Richard K. Bogan, MD, FCCP, and Mary B. O'Malley, MD, PhD
}

To request a published supplement, please E-mail ks@mblcommunications.com Supported by an educational grant from Jazz Pharmaceuticals. 